\title{
Anaesthesia Practice
}

Neal H. Badner MD FRCPC,

Rosemary A. Craen MBBS FANZCA, *

Terri L. Paul MD FRCPC, ${ }^{\dagger}$

Jacqueline A. Doyle RN*

\section{Anaesthesia preadmission assessment: a new approach through use of a screening questionnaire}

Purpose: The preadmission assessment of patients one to two weeks preoperatively has become the standard across North America. We have devised a new approach that utilises a preoperative screening questionnaire, and this study attempted to determine the effectiveness of this technique.

Methods: Over six weeks, the attending anaesthetist for each patient undergoing non-cardiac surgery processed through the preadmission clinic (PAC) completed a study survey. This survey questioned if the assessment was appropriate with reasons, the consequences of no assessment, and if time was saved/lost on the day of surgery.

Results: Three hundred and seventy patients were processed (243 same-day (SD), I I I outpatient (O/P), and I6 inpatients (I/P)). Of these, 224 were assessed in the PAC ( 101 by medicine, 84 by anaesthesia and 39 by both): $42 \%$ (94) based on the questionnaire, 12\% (26) due to consultation, and 46\% (104) due to positive questionnaires and consultation. The physician assessments were appropriate $184 / 219(84 \%)$ times, inappropriate in $35(16 \%)$, while there was no answer for five. Assessments were inappropriate because $25 / 35$ (71\%) were unnecessary, while in nine (26\%) the patient was not optimised. Of the patients not assessed in the PAC only $9 / 145(6 \%)$ should have been assessed.

Conclusion: The use of our screening tool in combination with direct referrals appropriately determines assessment needs of patients and allows for more efficient use of medical personnel in the PAC.

Objectif : L'évaluation des patients en clinique de préadmission une à deux semaines avant l'intervention est devenue la norme en Amérique du Nord. Nous avons élaboré une nouvelle approche utilisant un questionnaire de dépistage préopératoire et cette étude vise à valider cette approche.

Méthodes : Sur une période de six semaines, l'anesthésiste assigné à chaque patient prévu pour une chirurgie non cardiaque et s'étant présenté à la clinique de préadmission (CPA) a complété une enquête. Cette étude évaluait si la visite en CPA était appropriée et en donnait les motifs, évaluait les conséquences d'une absence de visite et si cette démarche économisait du temps le jour de la chirurgie.

Résultats : Trois cent soixante-dix patients ont participé à cette démarche: 243 en chirurgie d'un jour (SD), I I I en ambulatoire (O/P) et 16 comme hospitalisés (I/P). Parmi ceux-ci, 224 ont été évalués à la CPA (IOI par la médecine, 84 par l'anesthésie et 39 par les deux): $42 \%$ (94) d'après le questionnaire, 12\% (26) d'après la consultation et $46 \%$ (104) suite à un questionnaire et une consultation positifs. L'évaluation par un médecin était appropriée dans 184/219 (84\%) des cas, inappropriée dans 35 cas (16\%), alors qu'aucune réponse n'était obtenue dans cinq cas. L'évaluation par le médecin était inappropriée parce que dans $25 / 35$ cas (71\%) elle était superflue alors que dans 9 cas (26\%), la condition du patient r'était pas optimale. De tous les patients non évalués à la CPA, seulement $9 / 145(6 \%)$ auraient dû l'être.

Conclusion : L'utilisation de notre outil de dépistage combinée à des consultations directes détermine correctement s'il faut évaluer les patients et permet d'utiliser plus efficacement le personnel médical de la CPA.

From the Departments of Anaesthesia* and General Internal Medicine ${ }^{\dagger}$ University Campus, London Health Sciences Centre, 339 Windermere Road, London, Ontario N6A 5A5.

Address correspondence to: Dr. N.H. Badner, Department of Anaesthesia, London Health Sciences Centre, University Campus, 339

Windermere Road, London, Ontario, Canada N6A 5A5. Phone: 519-663-3022; Fax: 519-663-3079; E-mail: nbadner@i)julian.uwo.ca Accepted for publication October $23,1997$. 
$\mathrm{T}$

HE preadmission assessment of patients one to two weeks before surgery has become the standard across Canada, ${ }^{1}$ the United States, ${ }^{2,3}$ Australia ${ }^{4}$ and England. ${ }^{5}$ Most of these clinics have a staff anaesthetist or a resident evaluate every sameday (SD) surgery patient. Since many patients are healthy and do not require further medical management, a physician assessment seems unnecessary and may strain physician resources. Indeed, this routinely occurs when patients are scheduled for outpatient $(\mathrm{O} / \mathrm{P})$ surgery. In other clinics, anaesthetists evaluate only those patients referred by the surgeon. ${ }^{6}$ This approach has the potential of missing important coexisting disease that may require further investigation. ${ }^{7}$ Our institution has devised a hybrid model, that utilises a preoperative questionnaire designed to determine the patient's health status. We use this questionnaire for patients scheduled for both SD and $\mathrm{O} / \mathrm{P}$ surgery. In our approach, patients are assessed by a physician if they have a positive questionnaire, or if they are referred by a surgeon, or if the patient requests an assessment. This study was designed to determine the effectiveness of our approach.

\section{Methods}

When patients are booked for $\mathrm{SD}$ or $\mathrm{O} / \mathrm{P}$ surgery they are given the preoperative questionnaire (Appendix 1) by the surgeon's office, which, when completed, is forwarded to the preadmission clinic (PAC) where it is reviewed by a nurse. For patients undergoing non-cardiac surgery, an assessment is made by a staff anaesthetist if there are positive responses to the questionnaire (questions \#1-8, $10-14,16,19-25$, or 30) and the patient is scheduled to undergo outpatient surgery or if a specific anaesthesia related issue is identified (questions \#27,28 and 36 when body mass index $>40$ ). If the procedure requires sameday admission and there are positive responses, an assessment is performed by a staff internist. If necessary, after the initial assessment, the anaesthetist or internist can have the patient assessed by the other service during the clinic visit. The surgeon may also consult one or both services directly and the patient may request to see either service directly. Patients not requiring a physician assessment and scheduled for SD surgery still attend the PAC to receive perioperative information from nurses and other paramedical personnel that includes brochures and videos describing anaesthesia and postoperative pain management modalities. During the study period the PAC was staffed by an anaesthetist four days a week and an internist daily.

Following institutional review board approval we prospectively evaluated this screening procedure over six weeks. During this period, the attending anaesthetist for each patient processed through the pread- mission clinic was asked to complete a separate study survey (Appendix 2) on the day of surgery. This anaesthetist survey questioned the appropriateness of the assessment, asked the likely consequences if no assessment had been made, and requested the anaesthetist to give an estimation of any time that would have been saved or lost on the day of surgery based on the assessment or the lack thereof.

\section{Results}

There were 370 patients processed through the PAC (243 SD, $111 \mathrm{O} / \mathrm{P}$, and 16 as inpatients) in the six week period. Of these 224 were assessed in the PAC (101 by medicine, 84 by anaesthesia and 39 by both), $42 \%$ (94) based on the questionnaire alone, $12 \%(26)$ due to consultation request alone, and $46 \%$ (104) duc to both positive questionnaires and consultation requests.

The assessments were considered to have been appropriate in $184 / 219(84 \%)$ patients, inappropriate in 35 (16\%), while the anaesthetist gave no answer (N/A) for 5 (Figure 1). The assessments were felt to be inappropriate because $25 / 35(71 \%)$ were unnecessary, while in nine $(26 \%)$ the patient was not optimised or did not have the appropriate laboratory tests performed and there was one N/A. If the 184 appropriate assessments had not been performed, the attending anaesthetist would have cancelled 21 (11\%), delayed for more history in $50(27 \%)$, or ordered more tests for $19(10 \%)$ patients, for a mean estimated delay of $20 \pm 23 \mathrm{~min}$. However, for 91 (49\%) patients the attending anaesthetist would have done the case without any change in the patients' management, while no answer was given three times.

One hundred and forty-six patients were not assessed by a physician. The attending anaesthetists felt that only $9 / 146(6 \%)$ of these patients should have been assessed.

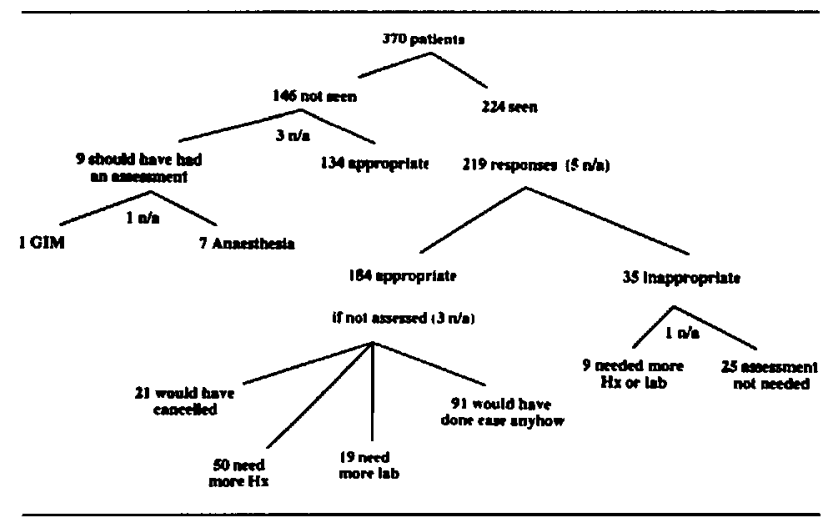

FIGURE 1 Patient breakdown based on assessment (yes/no), followed by appropriateness (yes/no) and response if the assessment had not been performed. $\mathrm{n} / \mathrm{a}=$ no answer. 
This assessment should have been by an anaesthetist seven times and an internist once, (one survey had no answer). Nevertheless, none of these cases was canceled. Four underwent surgery without change in management, while four had surgery after a delay. This delay was to obtain more history in two patients and extra laboratory testing in the two others. The anaesthetists involved estimated that this produced a delay of $6.3 \pm 3.2 \mathrm{~min}$.

Of the 370 questionnaires 198 were considered positive and 172 negative (Figure 2). The assessment was felt to be appropriate for $164 / 198(83 \%)$ positive questionnaires though $26 / 198(13 \%)$ were unnecessary. The negative questionnaires were appropriately not seen 142/172

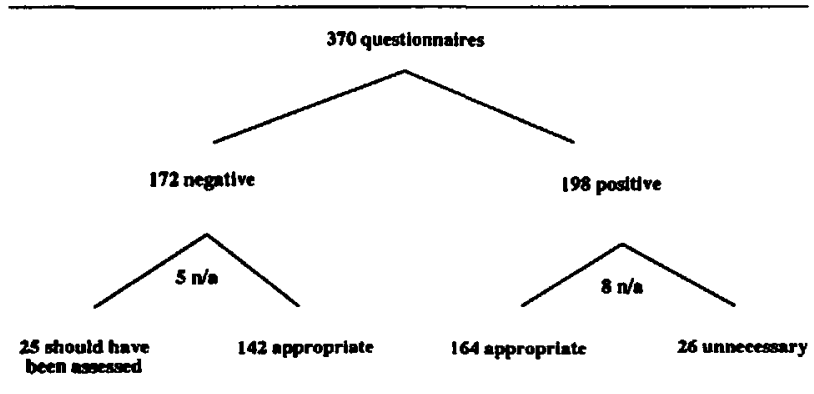

FIGURE 2 Patient breakdown based on questionnaire responses, followed by appropriateness of the assessment (yes/no). $\mathrm{n} / \mathrm{a}=$ no answer

TABLE I Statistical analysis of the preadmission process

\begin{tabular}{lll}
\hline Process Epidemiologic Assessment & Anaesthetist's view \\
\hline PAC assessment & should see & not necessary \\
seen & 184 & 35 \\
not seen & 9 & 134 \\
\hline
\end{tabular}

sensitivity $=184 /(184+9)=95 \%$

specificity $=134 /(134+35)=79 \%$

positive predictive value $=184 /(184+35)=84 \%$

negative predictive value $=134 /(134+9)=94 \%$

TABLE II Statistical analysis of the screening questionnaire

\begin{tabular}{lll}
\hline \multicolumn{2}{l}{ Questionnaire epidemiological assessment } \\
\multicolumn{3}{c}{ Anaesthetist view } \\
\hline questionnaire & should see & not necessary \\
positive & 164 & 26 \\
negative & 25 & 142 \\
\hline
\end{tabular}

sensitivity $=164 /(164+25)=87 \%$

specificity $=142 /(142+26)=85 \%$

positive predictive value $=164 /(164+26)=86 \%$

negative predictive value $=142 /(142+25)=85 \%$
(83\%), but the anaesthetists felt $25 / 172$ (15\%) should have been seen. There were 26 patients seen by surgeon request alone and, of these, $16(62 \%)$ were felt appropriate, $8(31 \%)$ were not, while in two no answer was given.

If one assumes that the attending anaesthetist is considered the gold standard as to the necessity of patients requiring an assessment in the PAC, our process had a sensitivity of $95 \%$, specificity of $79 \%$, positive predictive value (PPV) of $84 \%$ and a negative predictive value (NPV) of $94 \%$ as shown in Table I. A similar analysis of the questionnaire alone is shown in Table II. Utilising the questionnaire alone would increase the specificity to $85 \%$ and PPV to $86 \%$ at the expense of a decrease in the sensitivity to $87 \%$ and NPV to $85 \%$.

\section{Discussion}

Preadmission clinics have been created in Canada, ${ }^{1}$ the United States, ${ }^{2,3}$ Australia ${ }^{4}$ and England ${ }^{5}$ as a cost effective way to reduce surgical patient length of stay. Most of these clinics have either a staff anaesthetist or a resident evaluate every patient booked for same-day surgery. This seems unnecessary since many patients are healthy and do not require further physician assessment. Indeed, the same patients presenting for $\mathrm{O} / \mathrm{P}$ surgery are not routinely assessed. Other clinics have anaesthetists evaluate only those patients referred by the surgeon. ${ }^{6}$ Since surgeons are not always aware of the full medical history and/or the potential anaesthetic problems, this approach has the potential of missing important coexisting disease that requires further consultation. ${ }^{7}$ This, in turn, can lead to delays or cancellations in the operating room schedule as the attending anaesthetist attempts to investigate a disease state at the last minute.

At University Campus of the London Health Sciences Centre a hybrid model somewhat similar to others was devised. ${ }^{4}$ All patients booked for same-day or outpatient surgery complete a preoperative questionnaire (Appendix 1). The questionnaire was designed to determine their health status and was based on the knowledge of preoperative patient information important to anaesthetists. ${ }^{8}$ Interestingly, in the study by Lee et al., age and specific procedures were important factors requiring referral though we have not found them necessary in our model. We felt, as a recent survey of Calgary anaesthetists revealed, that healthy patients, i.e., those with negative questionnaires do not require physician assessment in the PAC. ${ }^{9}$ On the contrary, patients booked for $\mathrm{O} / \mathrm{P}$ surgery with severe medical disease should be assessed by a nonsurgical physician. This is a process that is not routinely performed, and one that is not easily predicted based on ASA status and surgical procedure alone. ${ }^{10}$ 
We have also devised a collaborative approach between anaesthesia and internal medicine different from most anaesthesia-only based services though somewhat similar to Hunt et al. ${ }^{11}$ In this model all patients are assessed by an anaesthetist who, if necessary, will consult an internist. In our system, if the procedure is to be performed on a same-day admission basis an internal medicine assessment is performed first. This was based on the fact that at our institution hospitalised postoperative patients have their medical management directed by internal medicine specialists. Therefore, an initial preoperative assessment, if necessary, is performed by an internist. In our opinion, to have an anaesthetist also assess these patients routinely would be excessive. Conversely, medical problems in outpatients are routinely managed by the anaesthetist and the initial assessment, if appropriate, is made by an anaesthetist. If necessary, however, after the initial assessment, the anaesthetist or internist may have the patient assessed by the other service during the clinic visit. In addition to the questionnaire response, the surgeon can directly refer patients for consultation with either an anaesthetist or an internist.

Many anaesthetists feel that the preadmission assessment of patients is their role alone and may question the value of an internal medicine assessment preoperatively. From the patient's perspective the whole perioperative period is of concern and if obtaining good postoperative care requires a GIM assessment our anaesthesia department felt patients having both a GIM and anaesthesia assessment was unnecessary. Indeed, more than half the assessments in our study were made by internists, yet $84 \%$ of all the assessments were felt appropriate. This approval rating is similar to that found by Lee $e t a l$., who used a similar screening process, but assessments were made only by anaesthetists. ${ }^{12}$ Patients can request an anaesthesia assessment in our system, but this is not a common occurrence and none did so in the study period. We did not assess patient satisfaction in this study, but anecdotal comments from patients have indicated a high level of satisfaction with our process. This is consistent with the recent findings of Biswas and Turpin who noted no change in patient satisfaction with the introduction of anaesthesia-only assessments in the PAC. ${ }^{13}$

This process of positive questionnaires and/or surgeon referral has a sensitivity of $95 \%$ and specificity of $79 \%$ when the attending anaesthetist is used as a gold standard. The utility of using only the preoperative patient questionnaire would have increased specificity at the expense of a decreased sensitivity. Currently, our institution's PAC processes 100-150 same-day or outpatient surgical patients per week. Though it would be ideal to assess every patient by an anaesthetist, it is not practical since our anaesthetists can only see $50-75$ patients/week, and our approach seems to be a reasonable compromise. Indeed the most common reason consults were felt to be inappropriate was that they were felt to be unnecessary. We therefore plan to evaluate our questionnaire and preadmission process further to address this.

The major limitations of this study are the lack of blinding and the subjective nature of the anaesthetist's responses. Since the preadmission assessment includes taking a more detailed history and obtaining further laboratory investigations, blinding the attending anaesthetist would have removed this data from the chart which would have been unacceptable. Indeed our study showed that the attending anaesthetists would have canceled or delayed their cases to obtain more history $38 \%$ of the time. A recent study investigating unanticipated intraoperative events in patients assessed at a preanaesthetic clinic used a similar unblinded approach. ${ }^{12}$

In conclusion, we feel that the use of our screening questionnaire in combination with direct referrals appropriately determines assessment needs of patients booked for non-cardiac same-day or outpatient surgery. This enables medical personnel in the PAC to assess patients needing further medical investigation or management.

\section{Acknowledgment}

We wish to thank the members of the Department of Anaesthesia for their assistance and Catherine Hawke for her secretarial support.

\section{References}

1 Bootbe P, Finegan BA. Changing the admission process for elective surgery: an economic analysis. Can J Anaesth 1995; 42: 391-4.

2 Fischer SP. Development and effectiveness of an anesthesia preoperative evaluation clinic in a teaching hospital. Anesthesiology 1996; 85: 196-206.

3 Pollard JB, Zboray AL, Mazze RI. Economic benefits attributed to opening a preoperative evaluation clinic for outpatients. Anesth Analg 1996; 83: 407-10.

4 Kerridge $R$, Lee A, Latchford E, Beehan SJ, Hillman $K M$. The perioperative system: a new approach to managing elective surgery. Anaesth Intensive Care 1995; 23: 591-6.

5 Livingstone II, Shah N, Harvey M, Wastell C, Kitchin $N$. Role of pre-admission clinics in a general surgical unit: a 6-month audit. Ann Royal College Surg Eng 1993; 75: 211-2.

6 Conway JB, Goldberg J, Chung F. Preadmission anaesthesia consultation clinic. Can J Anaesth 1992; 39: 1051-7.

7 Hurtado C, Chung F, Krishnathas $A$. Does the nurse practitioner have a role in the pre-admission unit? Can J Anaesth 1996; 43: A61. 
8 Lee A, Lum ME, Hillman KM, Bauman A. Referral of surgical patients to an anaesthetic clinic: a decisionmaking analysis. Anaesth Intensive Care 1994; 22 : $562-7$.

9 Pagenkopf DS, Tang TK. Evaluation of changing practice in pre-anaesthetic assessment. Can J Anaesth 1995; 42: A35.

10 Mattison $R A$, Fleck $C$. Predicting the timing of ambulatory preanesthesia evaluation by ASA classification and surgical intensity score. Anesthesiology 1997; 87: A24.

11 Hunt WS, Holmboe ES, Thran MJ. Preoperative assessment: a collaborative approach between anesthesiology and internal medicine. Anesth Analg 1996; 82: S196.

12 Lee A, Lum ME, Perry M, Beehan SJ, Hillman KM, Bauman $A$. Risk of unanticipated intraoperative events in patients assessed at a preanaesthetic clinic. Can J Anaesth 1997; 44: 946-54.

13 Biswas IH, Turpin TJ. Effect of organized pre-anesthetic assessment clinic on patients perception of the role of anesthesiologists. Anesthesiology 1997; 87: A964.

\section{Appendix 1}

1 Have you ever had a heart attack?

2 Have you ever had heart trouble?

3 Have you ever had heart failure?

4 Have you ever had fluid in your lungs?

5 Do you have a heart murmur?

6 Did you have rheumatic fever as a child?

7 Do you ever have chest pain, angina, or chest tightness?

8 Have you ever been treated for an irregular heart beat?

9 Do you have high blood pressure?

10 Do you ever have difficulty with your breathing?

11 Do you have asthma, bronchitis, or emphysema?

12 Do you cough frequently?

13 Does climbing one flight of stairs make you short of breath?

14 Does walking one city block make you short of breath?

15 Do you now or have you recently smoked cigarettes? If yes, how many packs per day?

For how many years?

16 Do you have liver disease, or a history of jaundice or hepatitis?

17 Do you drink more than three drinks of alcohol per day? If yes, how many per week?

18 Do you have indigestion, heartburn, or a hiatus hernia?
19 Do you have a history of thyroid problems?

20 Do you have diabetes?

21 Do you have a kidney problem?

22 Do you have numbness or weakness of your arms or legs?

23 Do you have epilepsy, blackouts, or seizures?

24 Have you had problems with blood clots, or excessive bleeding?

25 Do you have any other important medical problems? Please list.

26 Have you ever had an anaesthetic? If yes, when was your last one?

27 Have you or any member of your family had a reaction to an anaesthetic?

28 Do you have arthritis or pain in your neck or jaw?

29 Do you have dentures, capped or loose teeth?

30 Do you think you may be pregnant?

31 Have you taken prednisone, steroid medication, or cortisone-like drugs in the past year?

32 Please list any food or medication allergies that you have:

33 Please list any medications you are currently taking:

34 Please list any operations you have had in the past:

35 If this is the day of surgery, when did you last eat or drink?

36 Age:__ Weight:___ (lbs or kg) Height:___ (inches or $\mathrm{cm}$ )

\section{Appendix 2}

1 Was this patient seen in consultation by a physician in the PAC? Yes, if so
No, go to $\# 6$

2 Was the assessment appropriate? Yes

because ___ problems delineated history clarified further information obtained further lab testing including

No, go to \#4 was ordered 
3 If the patient had not been seen, you would have:

_ done the case anyway

delayed

min to obtain more history

delayed ___ min to obtain lab test

_ cancelled the case

4 If the assessment was inappropriate, why?

_ patient not optimised

lab work:

lab work: not followed up not ordered

__ diagnosis missed

_ consult not necessary patient given wrong advice

5 Because of the answer to \#4 you did the case anyway delayed __ min to obtain more history delayed _ lab test: cancelled the case

\section{Questionnaire is finished}

6 Should the patient have been seen by a physician? Yes if so GIM anaesthesia

No, questionnaire is finished

7 This patient should have been seen because of: past medical history of: past anaesthesia history of: airway concern

8 Because of the answer to \#7 you did the case anyway delayed _ _ min to obtain more history

_ delayed _ min to obtain following lab test: cancelled the case

(booked time: 